\title{
On the syntactic derivation of negative sentence adverbials*
}

\author{
PAUL ROWLETT \\ University of Salford \\ (Received Is April 1992; revised 25 October 1992)
}

\begin{abstract}
We consider recent Government-Binding work on sentential negation, e.g. by Pollock, and evaluate a fundamental assumption made about the syntax of negative clauses. While accepting that ne is generated as the head of NegP, we reject the dual claim that pas is characteristically: (a) a maximal projection, and (b) base-generated as the specifier of ne. We offer a three-sided argument against such an analysis, invoking: (a) the incompatibility of the proposal with the status of pas as a nominal; (b) the interaction between pas, etc, and indefinite direct objects; and (c) the syntax of 'adverbials'. We go on to consider Obenauer's work on 'quantification at a distance' and Battye's work on 'nominal quantification'. On the basis of this work, we posit that pas is generated lower in clause structure, either VP-adjoined or as the head of a determiner-less direct object DP.
\end{abstract}

\section{INTRODUCTION}

In this article, cast within the GB framework (see Chomsky, I98I, I986a/b), we address the syntax of sentential negation in standard French, in particular those elements which receive a negative interpretation when they appear in association with negative ne, e.g. pas (not), plus (no longer), guère (hardly/ rarely), rien (nothing) and personne (no-one). Despite the fact that these elements (known as forclusifs in the traditional French grammatical literature) are common features of standard French, serious analysis of their syntax was missing from theoretical linguistics for a number of decades due to the lack,

* Some of this material has been presented at workshops and conferences at Cambridge (England), the University of York (England), the University of Ferrara (Italy), the University of Manchester (England) and the University of Girona (Spain), as well as at the North-West Centre for Romance Linguistics Workshop on French Syntax held at UMIST (England) which I coorganised with Chris Lyons and Paul Bennett. This article is a revised and abridged version of Rowlett (1992) and has benefited greatly from audience questions and comments, especially from Adrian Battye who read through and commented on earlier drafts. Our gratitude also to the comments of three anonymous JFLS reviewers and to Professor Jacques Durand for his support throughout. We thank all these people for their help. All errors remain our own. 
within the Chomskyan paradigm at least, of a sufficiently articulated model of sentence structure. This situation was rectified by Pollock (1989). Since then, a number of studies of sentential negation have appeared, e.g. Belletti, I990, Ouhalla, I990, Zanuttini, I991, Haegeman \& Zanuttini, I99I and Rivero, I99I. We shall refer to some of this work below.

Examples of the kind of negative structure we shall be considering are given in $(\mathrm{I})-(4)$ below, simple sentences containing intransitive and transitive verbs:

(I) Intransitive:
a. Elise fume.
b. Elise ne fume Pas/plus.
c. *Elise ne fume pLus pas/pas plus.

(2) Transitive (definite direct object):
a. Elise fait
ses devoirs.
b. Elise ne fait
PAS/PLUS
ses devoirs.
c. ${ }^{*}$ Elise ne fait
Plus Pas/Pas plus ses devoirs.

(3) Transitive (indefinite direct object):
a. Elise achète (régulièrement) un journal.
b.
des journaux.
c.
d. Elise n' achète PAS/PLUS
*de journal/-aux.
e.
*un journal.
f.
*des journaux.
de journal/-aux.

(4) Transitive (negative direct object):
a. Elise voit trois hommes et une femme.
b. Elise ne voit PERSONNE.
c. Elise ne voit PLUS PERSONNE.
d. *Elise ne voit PAS PERSONNE.
e. Elise boit le whisky.
f. Elise ne boit RIEN.
g. Elise ne boit PLUS RIEN.
h. ${ }^{*}$ Elise ne boit PAS RIEN.

Even in purely descriptive terms, this array of data illustrates the complex phenomenology represented by sentential negation in French. On the basis of our affirmative sentences (i.e. (Ia), (2a), (3a/b), (4a/e)) it is clear that various conditions determine the distribution of the elements under consideration:

I The distribution of ne .. pas/plus in sentences ( $\mathrm{I} b$ ) and ( $2 \mathrm{~b}$ ) seems 'straightforward' enough; ne precedes while pas/plus follows the finite verb.

2 Pas and plus cannot co-occur, in any order. See strings (Ic) and (2c).

3 Where the sentence contains a transitive verb governing an indefinite 
direct object, e.g. in (3), the situation is more complicated. In affirmative sentences, the direct object must be realised either with the singular indefinite article, as in (3a), or as a plural partitive structure, as in (3b), while, in negative sentences, it must be realised as what Selkirk (1977) terms a pseudo-partitive structure, as in (3f) (singular \& plural). (We shall give flesh to this terminological distinction in subsection 2.2 below.)

4 Where the direct object of a transitive verb is replaced, as it were, by a negative substitute argument, as in (4b/f), it can co-occur with plus, as in $(4 \mathrm{c} / \mathrm{g})$, where plus must be the former of the two items, but not pas, hence the ungrammaticality of $(4 \mathrm{~d} / \mathrm{h})$.

We do not intend to address all the issues raised by the above data and observations; rather we see our work here as a modest contribution to a wider research agenda aiming, ultimately, to provide a theory of sentential negation which can capture these data.

It is possible to distinguish between two types of element associated with $n e$ in these structures: (a) arguments, e.g. rien and personne, which receive a $\theta$-role, as in $(4 \mathrm{~b} / \mathrm{c} / \mathrm{f} / \mathrm{g})$; and, (b) non-arguments, e.g. pas and plus, which, presumably, receive no $\theta$-role, as in (Ib). Given their apparent status as non-arguments, the members of this second group can be said to have an adverbial function. Rather than identifying (albeit negatively) some participant within the discourse (like rien (the identification of what is (not) drunk) and personne (the identification of what is (not) seen)), the members of this group seem to modify the entire proposition in that, minimally, they negate it. As our title suggests, we shall be concentrating on the syntax of members of the second group of elements, i.e. negative sentence adverbials like pas. In particular, we wish to consider the position in clause structure in which these elements are base-generated. In our discussion, attention will be focused on the syntax of pas itself. The extent to which our account of the syntax of pas can be applied to other forclusifs, such as those exemplified in (I)-(4) above, will be left on the research agenda for the time being (but see Rowlett, forthcoming).

Our discussion will be structured in the following way. We begin, in section I, with a review of the background of recent GB work on sentential negation in Romance. As far as we can tell, Pollock's 'NegP' hypothesis has been generally adopted in the literature, e.g. Belletti, 1990, Zanuttini, I991, Haegeman \& Zanuttini, I99 I, Rivero, I99 I, Martineau, I992 ${ }^{1}$. In section 2, we concentrate on Pollock's claim, that pas is characteristically a maximal projection, base-generated in SpecNeg. Although this claim is quite compatible with X-bar theory, we argue on other grounds that it is in fact untenable. We go on, in section 3, to set the scene further with a review of recent work by Battye on 'nominal quantification' in French. In section 4, we

1 But see Williams (1991) who argues that pas is in fact the negator proper while ne is nothing more than a scope marker for sentential negation. For an attempt to integrate Williams' approach with the NegP hypothesis, see Rowlett (forthcoming). 
return to the issue at hand and argue that pas is best analysed, not as the Dstructure specifier of NegP, but rather as one of Battye's 'nominal quantifiers'. Our conclusions are brought together in the summary in section 5 .

\section{I.O. THE NEGP HYPOTHESIS}

In major recent comparative work, Pollock and Belletti (1990) have offered analyses of clause structure with particular reference to sentential negation in Romance. As part of his theoretical formalisation of the intuitive idea that verbal inflection encodes (at least) both agreement and tense features, Pollock claims that the familiar Infl node heading IP should be analysed in a much more articulated fashion. To be precise, Pollock posits a reanalysis of the single head I (heading IP, above VP), in terms of (at least) two heads, which he labels Agr and $\mathrm{T}$ and which independently encode agreement and tense features respectively. Thus, in Pollock's analysis of French and English clauses, the ultimate head of IP (renamed TP), T, encodes tense features only. Instead of selecting the lexical projection VP as its complement, $T$ selects a further functional projection, AgrP, the ultimate head of which, Agr, encodes agreement features only. It is the lower of these two functional heads, Agr, which finally selects VP as its complement. In this analysis, Verb Movement is reinterpreted as V-to-Agr-to-T movement, while I-to-C movement straightforwardly falls out as T-to-C movement.

Belletti's (1990) analysis is similar to Pollock's in a number of respects; one point on which the two researchers differ is with respect to the relative ordering of the functional projections TP and AgrP. Belletti (1990) posits that AgrP is the higher of the two projections, arguing that Baker's (I985) 'Mirror Principle' of morphology supports her analysis over Pollock's. The following examples of Italian ( $\$$ ) and French (6) verbs illustrate how this more articulated model of verbal inflection (together with Belletti's ordering of TP relative to $\mathrm{AgrP}$ ) can account for the data.

(s) a. Legg-eva-no

Read-imp-3pl

They read (imperfect)

(from Belletti, 1990:28)

(6) a. Arriv-ai-ent

b. Parl- er-ò

Speak-fut-lsg

I will speak

\section{b. Téléphon-er-as}

Here, the 'tense' suffix is closer to the root than the 'agreement' suffix. It is therefore argued that the features encoded under $T$ are 'incorporated', to use Baker's (1988) term, before those encoded under Agr. This is most straightforwardly captured if AgrP is positioned higher in clause structure than TP. Since this issue has no bearing on our discussion here, we shall adopt Belletti's relative ordering of $\mathrm{AgrP}$ and TP without further comment.

In addition to TP and AgrP, Pollock (1989:365) and Belletti (1990:29) assume (in negative clauses, at least) the presence of a further projection 
NegP. ${ }^{2}$ Pollock and Belletti suggest that NegP intervenes between TP and AgrP. ${ }^{3}$ See (7) below for a representation of the CP structure we shall be assuming throughout.

(7)

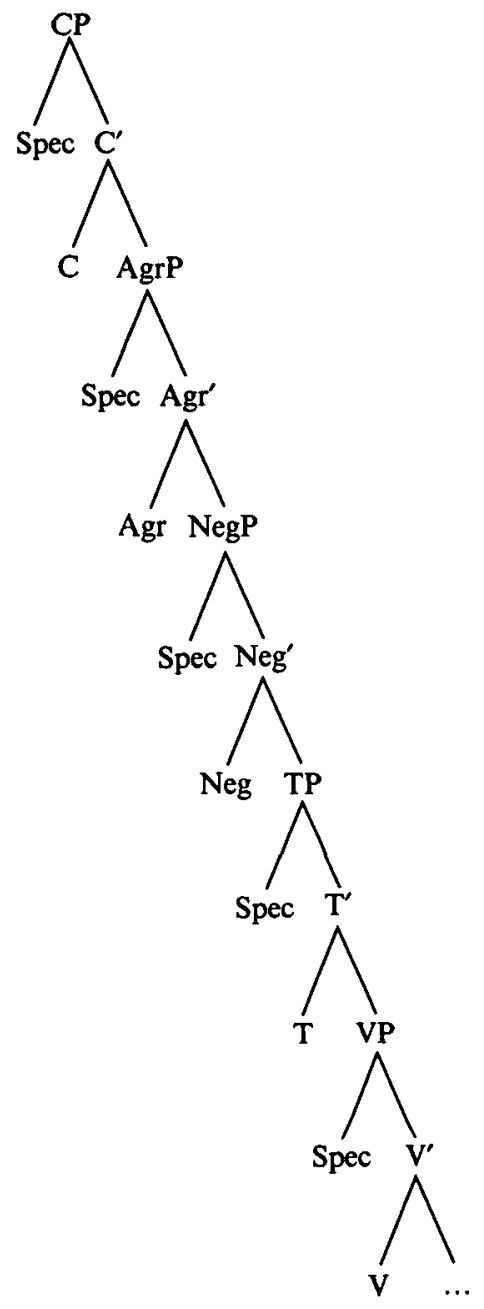

2 It could be argued that Pollock's NegP is in fact one realisation of what might better be labelled PolP (Polarity Phrase) present in all clauses. This would correspond to Laka's (1990) $\Sigma$ P, for example. The idea is supported by recent work by Belletti (1990; 1992) which suggests that, in Italian, a number of 'positive' sentence adverbials behave in very similar fashion to 'negative' sentence adverbials. However, the fact that, in a number of languages, verb syntax in positive clauses differs from verb syntax in negative clauses, could be an indication of some structural differences between positive and negative clauses, e.g. the presence vs. absence of NegP.

3 While endorsing the view that NegP intervenes between AgrP and TP in French, Ouhalla (1990) suggests that the position of NegP is determined by what he terms the Neg Parameter and is subject to variation cross-linguistically. A similar idea is proposed by Zanuttini (1991). Ouhalla suggests, for example, that French and English differ in this respect. 
Turning now to the specific details of negation in French, Pollock (1989:4 I4) and Belletti (1990:29) suggest that ne appears as the head of NegP, with pas as its XP specifier, as illustrated in the partial tree in (9) below. Here, pas enters into a specifier-head agreement relation with ne, presumably to satisfy the Neg Criterion in (8) proposed by Haegeman \& Zanuttini (1991:244), such that the two elements are interpreted as a single instance of negation.

(8) The Neg Criterion

a. Each $\mathrm{Neg} \mathrm{X}^{\circ}$ must be in a specifier-head agreement relation with a negative operator;

b. Each negative operator must be in a specifier-head agreement relation with a Neg $\mathrm{X}^{\circ}$.

(9)

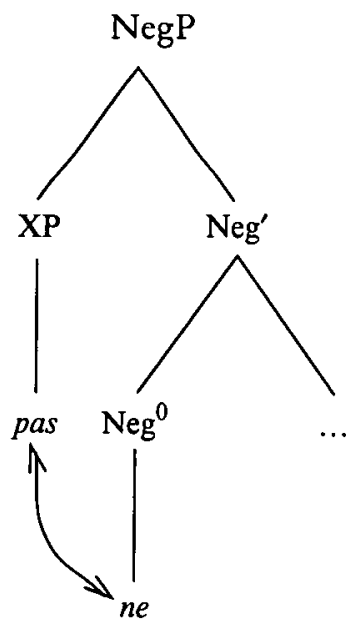

Spec-head

agreement

In this configuration, pas precedes ne at D-structure. The reverse ordering of these two elements at S-structure is analysed by Pollock (1989:414) as a consequence of the clitic nature of ne: it will always cliticise onto the higher Agr node. In finite clauses, e.g. (IOd), ne will cliticise onto the verb (which occupies the Agr node). Evidence to support the syntactic contiguity being postulated between ne and the finite verb comes from paradigms such as (Io) below. Where sentential negation co-occurs with subject-auxiliary inversion, as in examples (rod/e), the clitic form ne moves with the verb. Assuming that subject-auxiliary inversion involves movement from Agr to $\mathrm{C}$ (see (IOC)), it follows that the clitic ne must have adjoined to the verb under Agr (following Kayne's (I99I) analysis of cliticisation as adjunction to an agreement head) prior to movement to $C$. 
(1о) a. Il est venu.

b. Est-il $t$ venu?

c. [C [ ${ }_{\mathrm{Ii}}$ Est] ] -il $\left[\mathrm{I}_{i} t\right]$ venu?

d. Il n'est pas venu.

e. N'est-il $t$ pas venu?

f. [c [Ii $\left.\left.\mathrm{N}^{\prime} \mathrm{est}\right]\right]$-il $\left[{ }_{\mathrm{Ii}} t\right]$ pas venu?

(For opposing views on the interaction between the syntax of ne and Verb Movement, i.e. on how the finite verb and $n e$ become associated with the Agr position, see Ouhalla (1990:203), who posits successive cyclic V-to-Tto-Neg-to-Agr movement, and Roberts (199I; 1992), whose modified formulation of the Head Movement Constraint allows him to posit successive cyclic V-to-T-to-Agr movement followed by cliticisation of $n e$ to Agr. For a review of the proposed accounts, see Rowlett (1992:9-10).)

Having presented the relevant features of recent work on sentential negation in French, we would now like to reconsider one particular aspect of the work, i.e. the proposed analysis of pas.

\subsection{ARGUMENTS AGAINST THE PROPOSED ACCOUNT OF PAS}

We would like to accept Pollock's analysis of $n e$ as the head of NegP. We would like to reject the claim that pas is characteristically a maximal projection base-generated as the specifier of ne, i.e. in SpecNeg.

In section 4 below, we present and subsequently argue in support of our alternative analysis which, while true to the spirit of the NegP hypothesis, is compatible with insights by Battye and Obenauer (reviewed in section 3). In this section, we endeavour to justify our rejection of the Pollockian analysis of pas. Our argumentation will involve: (a) a suggestion that this analysis is incompatible with the status of pas as a nominal (section 2.I); (b) an analysis of the close relationship between pas and indefinite direct objects in negative clauses (section 2.2); and, (c) a consideration of the general nature of 'adverbials' and the theory of grammar (section 2.3).

\section{I. The status of pas and $\theta$-theory}

Our first argument against the (now classical) Pollockian analysis of pas hinges on two premises. The first concerns the categorial status of pas; the second relates to a distinction between functional and lexical categories with respect to $\theta$-theory. A surprising feature of Pollock's formulation of the NegP hypothesis with respect to French, and subsequent reworkings of his basic idea by other researchers, is that, while suggesting that the element pas is base-generated in SpecNeg and, hence, a maximal projection, no proposal is made with regard to its syntactic category. Pas appears in tree diagrams under an unlabelled node. This is particularly surprising since proposals have 
appeared in the literature as to the categorial status of this element. Battye (1989), for example, suggests that the pas in ne . . pas is a nominal just like the pas in faire un pas en avant. This analysis is credible if one considers that both pas (not) and pas (step) derive from the Latin nominal passum (step). We shall assume this to be the correct categorial analysis of pas (not).

With this in mind, we turn now to a difference between functional and lexical categories with respect to $\theta$-theory. The distinction is by no means new; rather, it reflects the distinction made in traditional grammar between 'content' words and 'form' words. The principles of X-bar syntax apply not only to the projections of lexical heads, but functional heads as well such as: complementisers (C), inflection (I) (i.e. tense ( $T$ ) and agreement $(\mathrm{Agr})$ ), determiners (D) and, presumably, negators/polarity items $(\mathrm{Neg} / \mathrm{Pol} / \Sigma)$.

Over and above the intuitive distinction between functional and lexical categories, functional categories can be distinguished from lexical categories in more formal terms. First, functional categories cannot be exhaustively characterised using Chomsky's (1974) putatively universal primitive syntactic features $[ \pm N]$ and $[ \pm V]$, whereas lexical categories can: noun $=[+\mathrm{N},-\mathrm{V}]$; verb $=[-\mathrm{N},+\mathrm{V}]$; adjective $=[+\mathrm{N},+\mathrm{V}]$; preposition $=[-N,-V]$. Second, the members of the set of functional categories form an essentially closed set, allowing little if any creativity, e.g. in the class of complementisers and determiners. Third, and most importantly for our purposes, it is assumed that functional categories are non-thematic $\left(\theta^{\prime}\right)$ elements in the sense that functional heads, unlike lexical heads, characteristically do not assign $\theta$-roles to their specifier or complement positions.

Returning to Pollock's analysis of negative clauses in French, we assume, with Zanuttini, for example, that Neg is a functional rather than a lexical category. While we do not have any immediate theoretical basis for this assumption, it does seem intuitively correct. (Note also that Ouhalla's (1990) concept of 'parameter' together with his formulation of the Neg Parameter, mentioned in footnote 3 above, is dependent on the status of Neg as a functional rather than a lexical category.) Furthermore, the set of items which can be substituted for ne, for example, is the empty set. Ne (or its non-clitic equivalent non) is the only (non-null) element which can appear as the ultimate head of NegP. Lexical creativity does not get much more restricted than this! It certainly looks as though we have prima facie grounds for classifying Neg among the set of functional categories.

Classifying $\mathrm{Neg}$ as a functional head and pas as a nominal, we can object to Pollock's analysis of pas in terms of $\theta$-theory. By postulating that the nominal pas is base-generated in SpecNeg, it could not be assigned a $\theta$-role. If we postulate, rather, that pas is generated elsewhere, i.e. in a $\theta$-position, lower in clause structure (without ruling out subsequent movement of pas to SpecNeg at S-structure or LF), we are able to satisfy both $\theta$-theory and the Neg Criterion. This, then, is our first argument against Pollock's analy- 
sis of pas. Our second argument involves the close relationship between pas and indefinite direct objects.

\subsection{The contiguity between pas and indefinite direct objects}

In this subsection, we shall consider the familiar distributions in (I I)-(I 13 ) below which are similar to those illustrated in (3) above. We would like to argue that Pollock's claim that pas is generated in SpecNeg, i.e. outside VP, is unable to account for the data.

(I I)
a. Elle me donne DE L' argent.
b. Elle me donne ' $D$ ' argent.
c. Elle ne me donne pas "DE L' argent.
d. Elle ne me donne pas D' argent.

(I2) a. Elise veut

b. Elise veut

c. Elise veut

d. Elise ne veut

e. Elise ne veut

UN frère.

f. Elise ne veut

(I3) a. Elise cherche

b. Elise cherche DES amants.

c. Elise cherche ${ }^{*} \mathrm{D}$ ' amant(s).

d. Elise ne cherche pas * UN amant.

e. Elise ne cherche pas *DES amants.

f. Elise ne cherche pas D' $\operatorname{amant}(s)$.

In each of the grammatical positive strings, i.e. (I I a), ( $12 \mathrm{a} / \mathrm{b}$ ) and ( $\mathrm{I} 3 \mathrm{a} / \mathrm{b}$ ), the indefinite direct object is introduced by what has been described as a partitive article ( $\mathrm{I}$ Ia), a plural indefinite article $(\mathrm{I} 2 \mathrm{~b} / \mathrm{I} 3 \mathrm{~b}$ ) or a singular indefinite article (I 2a/I 3a). Leaving to one side (I 2a/I3a), Battye (I99I, section 4: 37-4I) claims that the structure of the plural indefinite and partitive articles which introduce the direct objects in the affirmative sentences in $(\mathrm{I} 1 \mathrm{a} / \mathrm{I} 2 \mathrm{~b} / \mathrm{I} 3 \mathrm{~b})$ can, and therefore should, be given a unitary account. He goes on to offer such an account, which he labels 'partitive', after Selkirk. Not wishing to repeat Battye's work here, we shall limit ourselves to an illustration of the structure Battye proposes for these 'partitive' structures (1991:38). The tree structure in (I4) should make clear the unwarranted nature of the terminological distinction. Essentially, Battye analyses each of these direct objects - within the framework of Abney's DP-hypothesis - as an indefinite DP headed by an empty determiner [ $[\mathrm{D} 0]$ whose complement NP is headed by a variable. The complement of the variable is a PP headed by the preposition de. What is important is that this structure holds both for the so-called partitive and plural indefinite articles. 
(I4)

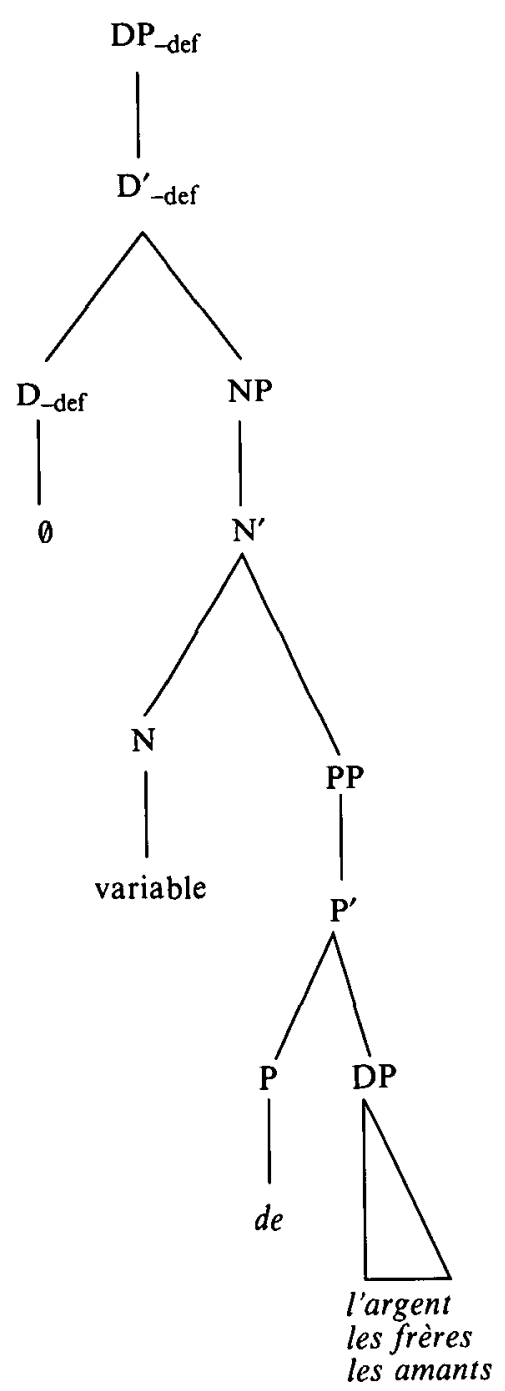

If we now consider the negative sentences ( $\mathrm{I} d / \mathrm{I}_{2} \mathrm{f} / \mathrm{I}_{3} \mathrm{f}$ ) above, something quite different is going on within the indefinite direct object. As the asterisks against string (I Ic), ( $12 \mathrm{~d} / \mathrm{e}) \&(\mathrm{I} 3 \mathrm{~d} / \mathrm{e})$ indicate, the co-occurrence of sentential negation, on the one hand, and an indefinite direct object introduced by Battye's 'partitive article' (or, indeed, the singular indefinite article), on the other, is unacceptable. That is to say, where sentential negation is present in a clause containing a verb governing an indefinite $D P$, the variable which heads the NP complement of the empty indefinite determiner cannot, in turn, take as its complement a PP headed by de. (These grammaticality judgements assume unmarked intonation. In fact, these strings can, with 
appropriate focalising intonation, be rescued and interpreted. See Rowlett (forthcoming) for a proposed account.)

In examples ( $I I d / I 2 f / I 3 f)$ above, then, there is a relationship between sentential negation and the structure of the indefinite direct object. The positive sentence in ( $\mathrm{I}$ I a) allows the indefinite direct object to be realised as a partitive structure, i.e. de l'argent, while the negative sentence in (I Id) obliges the direct object to be realised as a pseudo-partitive structure, i.e. d'argent, whereby the variable takes an NP complement, and the prepositional Case-marker de is adjoined to the NP for Case theoretic reasons. (See (I S) below.) This, in general terms, is the situation which has to be accounted for but which we feel Pollock's proposals fail to do.

(I5)

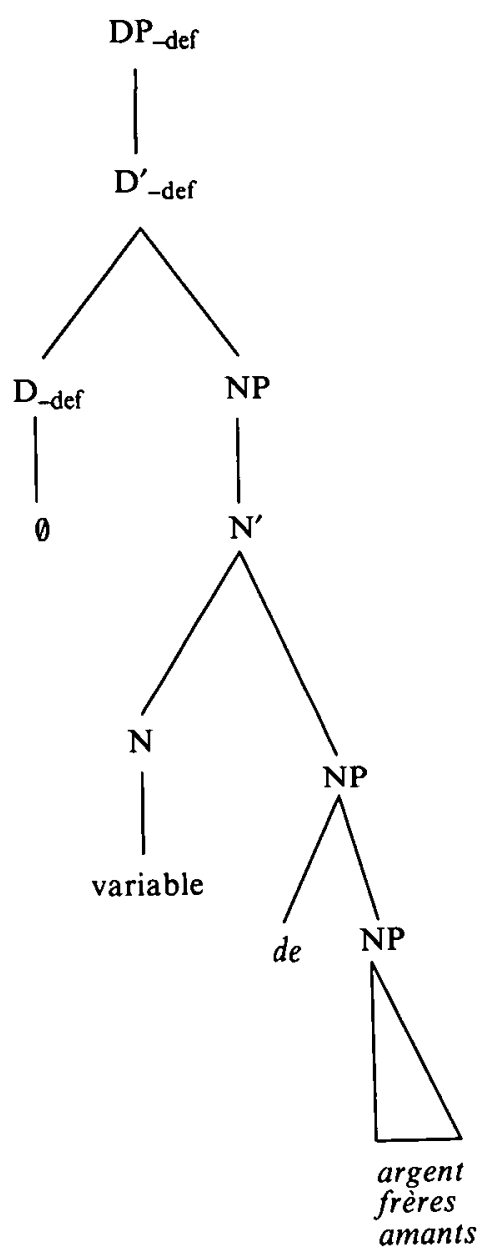


Without going into unnecessary detail, we would like to highlight one problematical issue which arises from these data if Pollock's analysis of pas is adopted. The problem was raised by one of the anonymous JFLS reviewers of Battye's (I99I) article who had difficulty accepting the claim that a variable could appear at D-structure with a complement. In Battye's analysis, the empty indefinite determiner, [D 0], subcategorises for an NP headed by a variable (at D-structure). Battye (199I:39) posits that the variable is bound by some empty operator present in Logical Form. Furthermore, the variable takes its own complement, i.e. a PP headed by $d e$. To avoid this situation, we would like to propose a slight modification to Battye's original (I99I) account. We would like to suggest that the empty operator whose presence Battye posits in Logical Form is in fact base-generated as the head of the complement of the empty indefinite determiner, i.e. in the position occupied by the variable in (I4). Further, we suggest that the operator moves, in Logical Form if not before, leaving a Case-marked trace, i.e. a variable, which the operator $\mathrm{A}^{\prime}$-binds in order to satisfy the familiar well-formedness condition on operator-variable pairs. In this way, we avoid the problem outlined above. The variable does not need to appear at D-structure since its appearance is the result of Move- $\alpha$. Consequently, since the PP headed by de is the complement of an operator at D-structure, we do not need to posit that a variable subcategorises for a complement.

This revision to Battye's (I99I) original proposals is relevant to our discussion of pas. In particular, in the same way that Battye suggests that an empty operator $A^{\prime}$-binds the variable in the partitive structure in (I4), so he suggests that the negative element pas, in SpecNeg according to Pollock, $\mathrm{A}^{\prime}$-binds the variable which figures in comparable negative structures, i.e. the pseudo-partitive structure illustrated in (I $s$ ) above. If this is indeed the case, we find ourselves in exactly the same situation which the reviewer found unacceptable about Battye's (199I) article. We would again have to suggest not only that a variable appears at D-structure but also that it subcategorises for a complement, here an NP. Not wishing to preempt the proposals we make below, we shall leave the issue in abeyance for the time being, returning to it with a proposed solution in section 4.

Of course, this problematical situation is partly a consequence of Pollock's claim that the element pas is base-generated in SpecNeg. This is therefore our second reason to doubt this aspect of Pollock's work. Having considered two rather theory-internal grounds for doubting the validity of the classical NegP analysis of pas, i.e. as the D-structure specifier of $n e$, we shall, in the next subsection, turn our attention to a less theory-specific reason for rejecting this feature of Pollock's article, i.e. a consideration of the syntax of adverbials. 


\subsection{The syntax of adverbials}

In this subsection, we endeavour to demonstrate that Pollock's account of pas is incompatible with its functional status as an 'adverbial'. By terming pas an adverbial, we mean no more than to say that negative pas clearly functions like a modifier of something. The similarities between negatives and adverbials did not in fact escape Pollock, who notes $(1989: 370,377)$ that there is 'a significant correlation in French between the placement of negation and that of adverbs' both in tensed and infinitival clauses. Given that pas can modify either another constituent, as exemplified in ( 16 ) below, or a proposition, as in the data we have reviewed so far, we would hope to be able to provide a unitary analysis of pas, i.e. one which is compatible both with its role in constituent negation and with its role in sentential negation. This is exactly what we intend to do.

(I6) a. A. Ça-va?

B: Pas mal!

b. A: Qui est-ce qui veut un café? B: Pas moi!

c. Pas vrai!

d. Pas possible!

e. A: T'as du fric?

B: Pas un sou!
How are you?

Not bad!

Who's for coffee?

Not me!

Never!

Impossible!

Got any money?

Not a penny!

Within the terms of X-bar grammar and primitive syntactic features, the categorial status of adverbs has traditionally been something of a thorny issue. The functional and distributional similarities which adverbs bear to adjectives have led some researchers (e.g. Emonds (1976:12)) to subsume the two types of element under the same category, i.e. adjective-cum-adverb, bearing the features: $[+N,+V]$. Similarly, and most importantly for our purposes, the structural configuration of adverbs runs parallel to that of adjectives. Given that adjectives are typically adjoined constituents, either to $\mathrm{N}^{\prime}$ or NP (within the DP-hypothesis), we shall assume that adverbs also appear in adjoined positions.

The question which this analysis of adverbs does not address involves adverbials, i.e. those constituents which do not necessarily bear the same categorial features as adverbs, but which nevertheless fulfil the same function. Given this identical function, we shall assume that they are licensed in tree-structures in the same way as adverbs, i.e. (Chomsky-)adjoined to the constituent which they modify. (Sportiche's (1988:429) 'Adjunct Projection Principle' and Chomsky's (1986b:I6) general theory of adjunction, together, oblige 'modifiers' to appear adjacent to their non-argument $\mathrm{X}^{\max }$ 'modifiee' or the head of their 'modifiee'.) Thus, the class of VP modifying adverbials will be adjoined to VP or V in the same way as VP adverbs. We are therefore 
arguing that adverbials are typically licensed in adjoined structures. We shall assume that adverbial pas is no exception. What is important is the fact that an analysis of a constituent like pas in terms of adjunction (i.e. with the structure: $\left[\alpha\right.$ pas $\left.\left[\begin{array}{ll}\alpha & \alpha\end{array}\right]\right)$ ) is clearly incompatible with Pollock's claim that pas is base-generated in SpecNeg. A specifier position is not an adjoined position.

Note also that, in Pollock's own presentation, not all negative adverbials are generated in SpecNeg. Pollock argues (1989:4I4) that the negative adverbials point, plus and guère are generated in 'a negative adverbial position in VP-initial position'. He is no more precise than this but we can assume some VP-adjoined position. If these elements are in fact VP modifying adverbials, we would endorse Pollock's claim. However, we do not agree with everything about Pollock's analysis of these negative adverbials. First, and contrary to Pollock, we would like to include pas within this category of elements. Second, we disagree with his claim (1989:4I4) that the entire NegP, headed by ne and with point, plus or guère in specifier position, is generated lower in the structure, i.e. adjoined to VP. This reservation notwithstanding, there is a clear need, acknowledged by Pollock, for some negative adverbials associated with ne to be generated lower in clause structure than SpecNeg.

Additional evidence to support an analysis which sees negative adverbials in French of the type under consideration here as being generated in (possibly VP-)adjoined positions is provided by Belletti (1990) in cross-linguistic work on Romance. According to Belletti (1990:57), 'negative adverbs' in Italian must be able to appear in some VP-initial position. As above, we can assume this to be some VP-adjoined position. Given that our objective is to arrive at a grammar which is as constrained as possible, it should in the first instance be assumed that this is the only type of position in which these 'negative adverbs' can be base-generated. The possibility that they can occupy different types of positions at D-structure should only be envisaged in the light of positive evidence. Therefore, where we have reason to assume that adverbs of this class appear in SpecNeg at S-structure, i.e. to satisfy the Neg Criterion in (8) above, we should look first towards an analysis in terms of movement which, all other things being equal, must be favoured over a model which allows these adverbs to be generated in more than one type of position, i.e. a VP-adjoined position on the one hand, and SpecNeg on the other. In view of the above considerations, it seems that a significant generalisation could be captured if all these 'negative adverbs' (including pas) could appear in a lower (adjoined) position and be subsequently raised to SpecNeg.

Having presented three independent arguments against Pollock's proposed analysis of pas, we would like to conclude this section by suggesting that the most important argument against Pollock's account of pas is the fact that there exists an alternative account of pas which elegantly characterises all 
the data which Pollock considers while avoiding the problems outlined above. In section 4, we elaborate and defend such an account. In section 3, we take something of an aside to consider some work by Battye and Obenauer, the results of which will be useful later.

\section{0. 'QUANTIFICATION AT A DISTANCE' AND 'NOMINAL QUANTIFICATION'}

Before offering a syntactic account of pas which, in our opinion, is compatible with the spirit of Pollock's NegP hypothesis, but which avoids some of the weaknesses of Pollock's implementation of the basis idea, we ask the reader to bear with us while we consider work by Obenauer $(1983 ; 1984)$ and Battye (1989; I99I). We acknowledge these authors at this point, and shall then take the liberty of not explicitly repeating our indebtedness in the course of the section. Consider (17):

(17) a. Le bouquiniste a vendu beaucoup de romans.

b. Le bouquiniste a vendu beaucoup des romans que tu lui as donnés.

c. Le bouquiniste a beaucoup vendu $t$ de romans.

d. Le bouquiniste a beaucoup vendu $t$ des romans que tu lui as donnés.

In the paradigm in (17), made familiar by Obenauer, beaucoup can be said, intuitively, pre-theoretically, to quantify the noun romans, irrespective of the fact that the scope of the quantification might be thought to differ between $(17 \mathrm{a} / \mathrm{b})$ on the one hand and $\left(\mathrm{I}_{7} \mathrm{c} / \mathrm{d}\right)$ on the other. In $\left(\mathrm{I}_{7 \mathrm{a}} / \mathrm{b}\right)$, the scope of the quantifier is restricted to the direct object of which it forms a part ([DP beaucoup [ de romans ]]), while in ( $17 \mathrm{c} / \mathrm{d})$, labelled 'quantification at a distance' (henceforth QàD) by Obenauer (1984), where beaucoup appears in some VP-initial position, the scope of the quantifier extends to the entire predicate. The semantic contrast is therefore reflected in the position of the quantifier. Elements which behave in similar fashion are trop, assez and peu. (Obenauer (1983:68; 1984: I 56) suggests that QàD structures are regarded as somewhat loose 'relâchê' by purists.)

The account of these structures adopted by Battye, following Obenauer, is hinted at by the symbol $t$ in ( $17 \mathrm{c} / \mathrm{d}$ ) above. As Battye terms it, 'the position marked $t$ is that with which the quantifier . . beaucoup . . . [is] associated' (Battye, 1991:23). Essentially, both Obenauer (working within an earlier model of TG) and Battye posit that, in ( $17 \mathrm{c} / \mathrm{d})$, i.e. where beaucoup does not appear within the direct object, the position which it would otherwise occupy within the direct object is filled by some null element. Thus, both researchers suggest that the direct objects in ( $17 \mathrm{c} / \mathrm{d})$ have the structure [NP EC [ de(s) romans ]], where EC represents an empty category of some kind. Both Obenauer and Battye assume that, in QàD structures, beaucoup and the empty category as 'linked' within the terms of Binding Theory, i.e. that the empty category is ( $A^{\prime}-$ ) bound by beaucoup. In Obenauer's (1983:68-9) 
terms, the empty category is 'localement lié par le quantifieur lexical qui . . . se trouve en position $A$ " ("locally bound by a lexical quantifier in an $\mathrm{A}^{\prime}$-position).

With respect to the question of whether this binding is a result of movement or not, Obenauer neither commits himself one way or the other, nor does he express any interest in the issue. Kayne (1975:29ff) and Battye (1991:23ff), however, are bolder on this point. In the case of the former, no movement is invoked in the relationship between beaucoup and the empty category (but see Milner (1978:690-2) for a critique of Kayne (1975:29ff)). In the case of the latter, the association between beaucoup and the empty category in these constructions is the relationship between an antecedent (in a pre-verbal $A^{\prime}$-position) and its trace. (What Battye (I99r:23) actually says with respect to QàD structures is that the quantifiers 'seemingly "float" backwards off the noun phrase in direct object position'. We have interpreted this as a movement approach to QàD, although Battye himself does not propose any structural analysis of the mechanics involved.) For our part, we would like to endorse the movement approach but postpone detailed discussion until section 4 where we shall be able to include negative sentence adverbials in our analysis.

A necessary corollary of Battye's (movement) analysis (according, at least, to Battye (I989)) is that the quantifier which appears, on the surface, either attached to or detached from the nominal it intuitively quantifies must also be able to function independently as an adverbial. This can be seen to be true in examples ( 18 ) below, where the quantifier appears in clauses containing either an intransitive verb (I8a) or a transitive verb governing a definite direct object (18b). Given that there is no indefinite direct object, beaucoup cannot possibly start out within, or be construed with, such a position.

(I8) a. J'ai beaucoup voyagé.

b. J'ai beaucoup applaudi la soliste.

This is not to say that the reverse also applies. As Milner (1978:690-2) illustrates, it is not the case that all adverbial elements which can function as in (I 8) can also function in association with the indefinite direct object of a transitive verb. For example, although both énormément and abondamment can appear as VP-adverbials, the former can appear in association with an indefinite direct object (both QàD and non-QàD) while the latter cannot, as illustrated in ( $\mathrm{r} 9 \mathrm{~b} / \mathrm{c})$ below, taken from Milner (1978:69I), his example (s3)).

(I9) a. J'ai énormément lu. / J'ai abondamment lu.

b. J'ai énormément lu de livres. / "J'ai abondamment lu de livres.

c. J'ai lu énormément de livres. / J'ai lu abondamment de livres.

Indeed, Milner uses these distributions to argue, contra Kayne (1975), that QàD structures are derived from non-QàD structures. His argument is centred on the ungrammaticality of "J'ai abondamment lu de livres which 
contrasts with the acceptability of J'ai abondamment lu. Kayne (1975) argues that elements like énormément/abondamment are base-generated in VP-initial position not only in (19a) but also in (19b) above. If this is indeed the case, we have to account for why both strings in (I9a) are acceptable while, in (Igb), only the string containing énormément is grammatical. If, alternatively, and as Milner proposes, the QàD strings in (Igb) are derived from the non-QàD strings in ( $19 \mathrm{c}$ ), then the unacceptability of the string in ( $19 b)$ containing abondamment can be accounted for in straightforward fashion. This particular element cannot appear in a (derived) QàD structure for the simple reason that it cannot appear in the equivalent (base-generated) non- $Q$ àD structure.

With respect to the syntactic category of this class of quantifier, Battye (I99I) claims that, unlike other quantifiers in French (where the term 'quantifier' represents a semantic rather than a syntactic characterisation), quantifiers like beaucoup are neither adjectives (cf. quelques) nor determiners (cf. plusieurs). Rather, Battye exploits Abney's (1987) DP-analysis to argue that these elements are in fact nominals, generated as the head of their own full NP complements of an empty D, i.e. as in (20) below. The reader will doubtlessly have noticed the similarities between what Battye is saying here about beaucoup and what he had to say regarding the traditional partitive article and plural indefinite article, which we reviewed in section 2.2 above. Here, beaucoup functions in similar fashion to the (nominal) operator we posited in those indefinite DPs, the difference being that, unlike the operator, which subcategorises for a PP complement, beaucoup can select either a PP or an NP complement (see $\left(\mathrm{I}_{4} / \mathrm{I}_{\mathrm{s}}\right)$ ). Thus, Battye calls this the class of 'nominal quantifier'.

(20) $\left[\mathrm{DP}\left[\mathrm{D}^{\prime} 0\left[\mathrm{NP}\left[\mathrm{N}^{\prime}[\mathrm{N}\right.\right.\right.\right.$ beaucoup $\left.\left.\left.\left.\left.] \mathrm{NP} / \mathrm{PP}\right]\right]\right]\right]\right]$

In summary, then, the members of the class of 'nominal quantifier' in French are characterised by a number of properties, namely: (a) they bear the syntactic features of nominals, i.e. $[-\mathrm{V},+\mathrm{N}]$; (b) they bear the pseudosemantic feature [+ quantification]; (c) they can be licensed as the head of the NP complement of an empty $D$ within an indefinite DP; (d) they are compatible with Q⿱亠̀口D; (e) they can function, independently of an indefinite DP, as a VP-adverbial.

As an alternative to Pollock's account of negative clauses in French, and of pas in particular, we would like, in section 4 below, to propose, after, e.g. Battye ( $1989: 29 \mathrm{fnI}$ ), that pas be subsumed under Battye's class of 'nominal quantifier'. That is, instead of analysing pas as a maximal projection, i.e. as the specifier of ne within NegP, we analyse this element rather as the head of an NP generated lower in clause structure, independently of NegP. We therefore posit that the categorial status of the element is 'noun', in exactly the same way that Battye (1989) analyses beaucoup, trop and assez as nouns. ${ }^{4}$

4 Consequently, contra Gaatone (1992:95), we suggest that negative de is the same de that appears in structures containing beaucoup, etc. 
(2I)

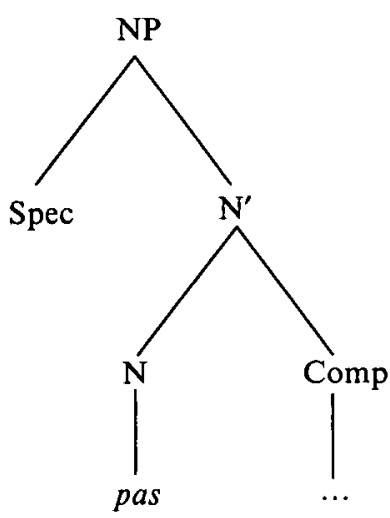

4.0. PAS AS A NOMINAL QUANTIFIER

In this section, we endorse the claim, made by Battye (I989:29 fn I I), that pas belongs to the class of nominal quantifier, with beaucoup, etc. In fact, in his own writing, Obenauer also subsumes (ne . . )pas under the same category of elements as beaucoup. (As mentioned above, Obenauer (1983; 1984) comments that $Q$ àD structures are regarded by purists as being somewhat loose. Presumably, he would not include QàD structures involving ne . . pas within this judgement!) Unlike Battye, Obenauer (1984: I55) analyses these elements as adverbs. Moreover, having illustrated the use of ne ... pas in QàD structures, Obenauer states quite explicitly that he does not intend to concern himself with any analysis of the syntax of sentential negation. In a somewhat similar vein, Battye (1989) includes pas in his inventory of 'nominal quantifiers' in a footnote, but goes no further. We would like to support Battye's claim that pas is a nominal. To do so, we shall endeavour to show that pas belongs to the same group of elements as beaucoup which we have already analysed as a nominal, after Battye.

First, like beaucoup and as predicted by Battye (1989), pas can be used, not only in association with indefinite direct objects, but also in clauses which do not contain indefinite direct objects, i.e. independently as an adverbial constituent, as in examples (22)-(25) below:

(22) a. Elise voyage

dans le nord de la France.

b. Elise voyage beaucoup

c. Elise ne voyage pas

dans le nord de la France.

dans le nord de la France.

(23) a. Elise a

b. Elise a

voyagé dans le nord de la France.

c. Elise n' a

beaucoup voyagé dans le nord de la France. pas voyagé dans le nord de la France.

(24) a. Elise aime

b. Elise aime beaucoup

c. Elise n' aime pas

les monuments de Paris.

les monuments de Paris.

les monuments de Paris. 
(25) a. Elise a

b. Elise a

c. Elise n' a aimé les monuments de Paris.

beaucoup aimé les monuments de Paris.

pas aimé les monuments de Paris.

As this array of data shows, pas not only fills the same slot, in linear terms, at least, as beaucoup; it also fulfils the same adverbial function.

Second, in the same way that the distribution of beaucoup in QàD structures is restricted (as discussed by Obenauer), so the distribution of pas seems to be subject to a similar restriction. To be precise, among the class of transitive verbs in French, Obenauer distinguishes between those which are compatible with QàD and those which are not. The first group is illustrated in (26) below (Obenauer's examples (6), ( $1983: 68)$ ), the second in (27) (Obenauer's examples (12), (1983:70)):

(26) a. Antoine a trop lu de romans policiers.

b. Max a (très) peu composé de sonates.

(27) a. "Le critique a peu apprécié de films.

b. *Son regard a beaucoup impressionné de minettes.

c. *La réorganisation a beaucoup accéléré de procédures.

d. "La nouvelle a beaucoup inquiété d'experts.

e. 'Une fois installé loin de la ville, il a beaucoup regretté d'amis.

Obenauer accounts for these differences in terms of what he calls 'VPquantification'. What Obenauer means by this is simply that, in QàD structures, i.e. where beaucoup, etc. are separated from the nominal they quantify, the quantification relationship is upheld by virtue of beaucoup, etc. quantifying the entire VP and, hence, the direct object. Working on the assumption that, where beaucoup appears in QàD structures, its adverbial reading is in terms of frequency as opposed to intensity (as a consequence of its original position within the direct object), QàD will not be possible with just those transitive verbs which are incompatible with a frequency reading for this class of quantifier, e.g. as in (27) above, which Obenauer classifies as intensity verbs. What is important here is that the appearance of pas in (QàD) structures containing transitive verbs from this group also produces strings which are bizarre, as illustrated in (28) below, which are otherwise identical to (27) above.

(28) a. *?Le critique n'a pas apprécié de films.

b. *?Son regard n'a pas impressionné de minettes.

c. *?La réorganisation n'a pas accéléré de procédures.

d. *?La nouvelle $n$ 'a pas inquiété d'experts.

e. *?Une fois installé loin de la ville, il n'a pas regretté d'amis.

Native speakers do not, in general, find these examples as unacceptable as the strings in (27), but rather as somewhat odd, especially examples (28c-e). One might reason that, although frequency adverbs are in theory incompatible with these transitive verbs, where that frequency is reduced to zero, i.e. 
with pas, the incompatibility is not as marked. So, while we accept that the fact that these strings are not considered totally unacceptable is a potential problem for our analysis here, we nevertheless conclude that pas belongs to the same class of quantifier as beaucoup. ${ }^{5}$

Having argued that pas can indeed be subsumed under the class of 'nominal quantifier' with beaucoup, we shall, in the following two subsections, attempt to provide a syntactic account which is compatible with all these items. We shall do this with respect to two quite distinct constructions. In section 4. I, we look at nominal quantifiers as used in sentences containing a transitive verb and an indefinite direct object. In section 4.2 , we turn our attention to other types of sentences. Finally, in section 4.3, we consider where our analysis leaves us with respect to other related issues.

\subsection{Pas as a nominal quantifier (in clauses containing a transitive verb and an indefinite direct object)}

In this subsection, we shall be assuming the basic structure in (29) below as the canonical D-structure from which sentences (I Id), (I2f) and (I $3 f$ ) above are derived:

(29) $\left[D P\left[s_{p e c} e\right]\left[D^{\prime}[D O]\left[N P\left[s_{p e c}\right.\right.\right.\right.$ e $]\left[N^{\prime}[N\right.$ pas $\left.\left.\left.\left.][N P N P]\right]\right]\right]\right]$

This structure is identical to (Is) above, except for the presence of the lexical nominal quantifier pas in the position occupied, in (IS), by the operator/ variable. Pas is the zero-level head of the NP complement of an empty determiner [D 0]. In turn, pas takes its own NP complement. As a nominal, pas will absorb the accusative Case assigned by the verb. Thus, for the NP complement of pas to receive Case, the prepositional Case-marker de is inserted at S-structure, as in (IS).

We shall account for the appearance of pas in QàD structures illustrated in (IId), (I2f) and (I3f) above derivationally, i.e. in terms of Move- $\alpha$. Given that we wish to maintain that pas is a member of the same class of 'nominal quantifier' as beaucoup and the operator discussed above, we shall endeavour to make our analysis compatible with all these elements.

If we first compare (29) above with Obenauer's original QP (Quantifier

5 If the situation were not murky enough already, the following data, brought to our attention by an anonymous JFLS reviewer, are not accounted for if pas is analysed along the same lines as beaucoup:

(i) a. Pierre n'a pas voulu de cadeau( $x)$

b. *Pierre a beaucoup voulu de cadeaux

(ii) a. Pierre n'a pas eu de peine

b. "Pierre a beaucoup eu de peine

However, it might be possible to resolve this problem with reference to Pollock's (1989:38991) observation that the past particples of French modals and être/avoir behave differently from other past participles. We shall not address this issue further here. 
Phrase) analysis of non-QàD structures in (30) below, a major difference between the two becomes apparent:

(30) [NP [QP QP ] de N']

The major difference concerns the status, in terms of X-bar theory, of the quantifier. In Obenauer's model, it is a maximal projection, namely, QP. In our model, nominal quantifiers are $\mathrm{X}^{\circ}$ (i.e. head $\mathrm{N}$ ) constituents, daughters of an $\mathrm{N}^{\prime}$ node and sisters of a maximal projection.

This difference is significant in that the versatility of Move- $\alpha$ is determined in part by the status, in terms of X-bar theory, of the relevant constituent. Although $\mathrm{X}^{\max }$ constituents can be adjoined to other $\mathrm{X}^{\max }$ constituents and can be raised into empty specifier positions, the movement which an $\mathrm{X}^{\circ}$ constituent can undergo is much more retricted. The only movement available to a head constituent is: (a) adjunction onto a higher head (see Kayne (I99I)), e.g. cliticisation; or, (b) incorporation into a higher head (see Baker (I988)), e.g. Verb Movement.

Thus, by positing that beaucoup is an $\mathrm{X}^{\max }$ constituent, Obenauer was able to argue that it can appear in some (adjoined) VP-initial position, either base-generated there or moved there courtesy of Move- $\alpha$. On the face of it, this is not going to be possible if we posit that beaucoup is a head. The constraints of X-bar theory will not permit a head to be basegenerated in a position adjoined to the maximal projection VP, while the constraints which apply to Move- $\alpha$ will now allow a head to be moved from a VP-internal $\mathrm{X}^{\circ} \mathrm{A}$-position to a VP-adjoined $\mathrm{X}^{\max } \mathrm{A}^{\prime}$-position. This is a problem which needs to be resolved if our account of the syntax of pas is to be compatible with the way we understand the behaviour of other nominal quantifiers, i.e. in terms of Obenauer's VP-quantification outlined above.

Our approach to this problem will hinge crucially on an initial application of Move- $\alpha$. Essentially, what is involved is the movement of a maximal projection (here the NP complement of pas, beaucoup, etc.) from within the direct object to an adjoined position, to the right of VP, as shown in (3I), which is not ruled out by the Case filter since the NP can take its Case-marker with it. (We are, of course, referring here to the pseudo-partitive article. In the case of the partitive article, the complement of the nominal quantifier is a PP which would not be subject to the Case filter.) 
Paul Rowlett

(3I)

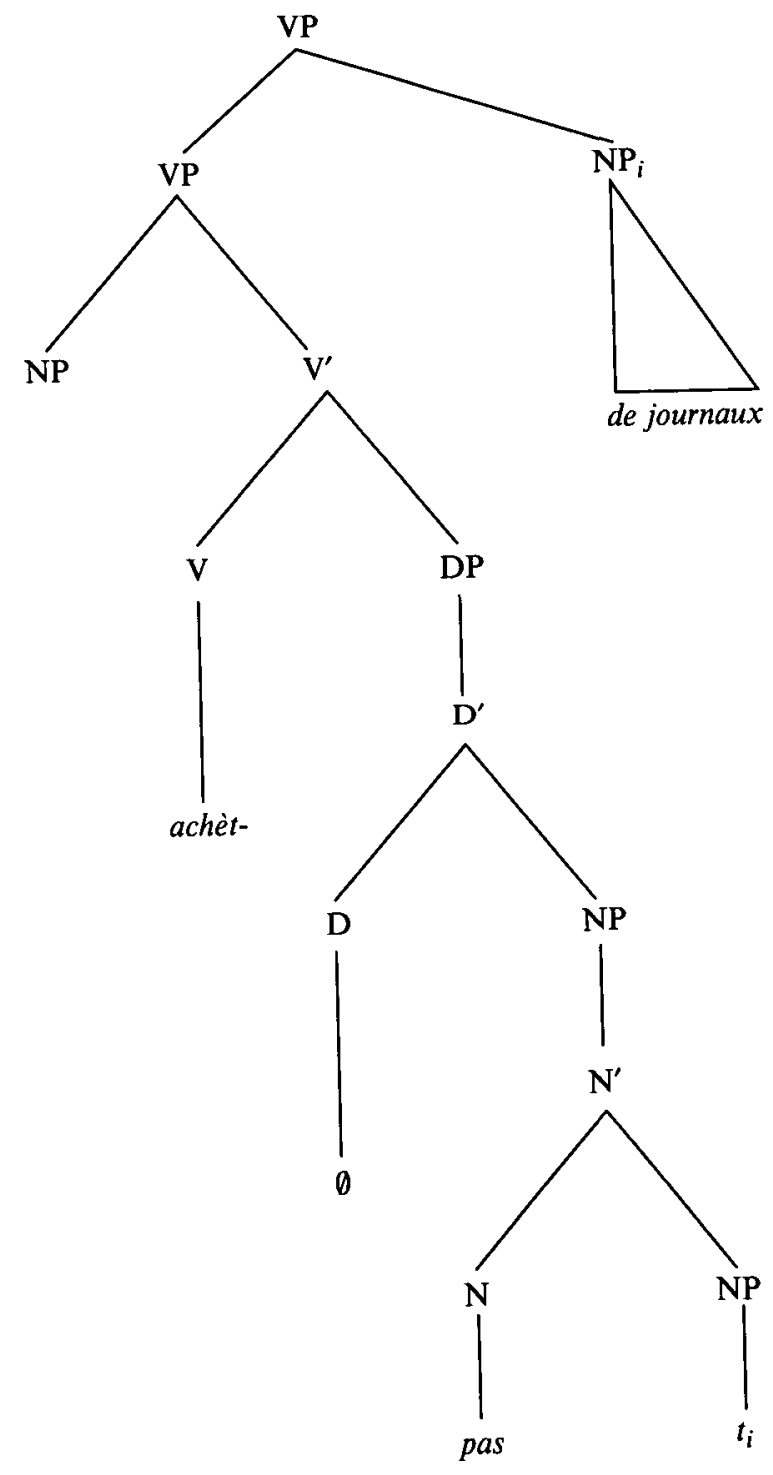

Once the complement of pas has been moved to the right, the DP of which pas is the head $\mathbf{N}$ is free to move independently, i.e. without taking its NP complement with it. Given Obenauer's analysis of the restriction which bars strings such as those illustrated in (27) and (28) above, i.e. VPquantification, we assume that Move- $\alpha$ adjoins this DP to VP, as illustrated in (32). (We therefore assume that the antecedent of the right VP-adjoined NP can properly bind its trace, the complement of pas, i.e. by reconstruction.) 
(32)

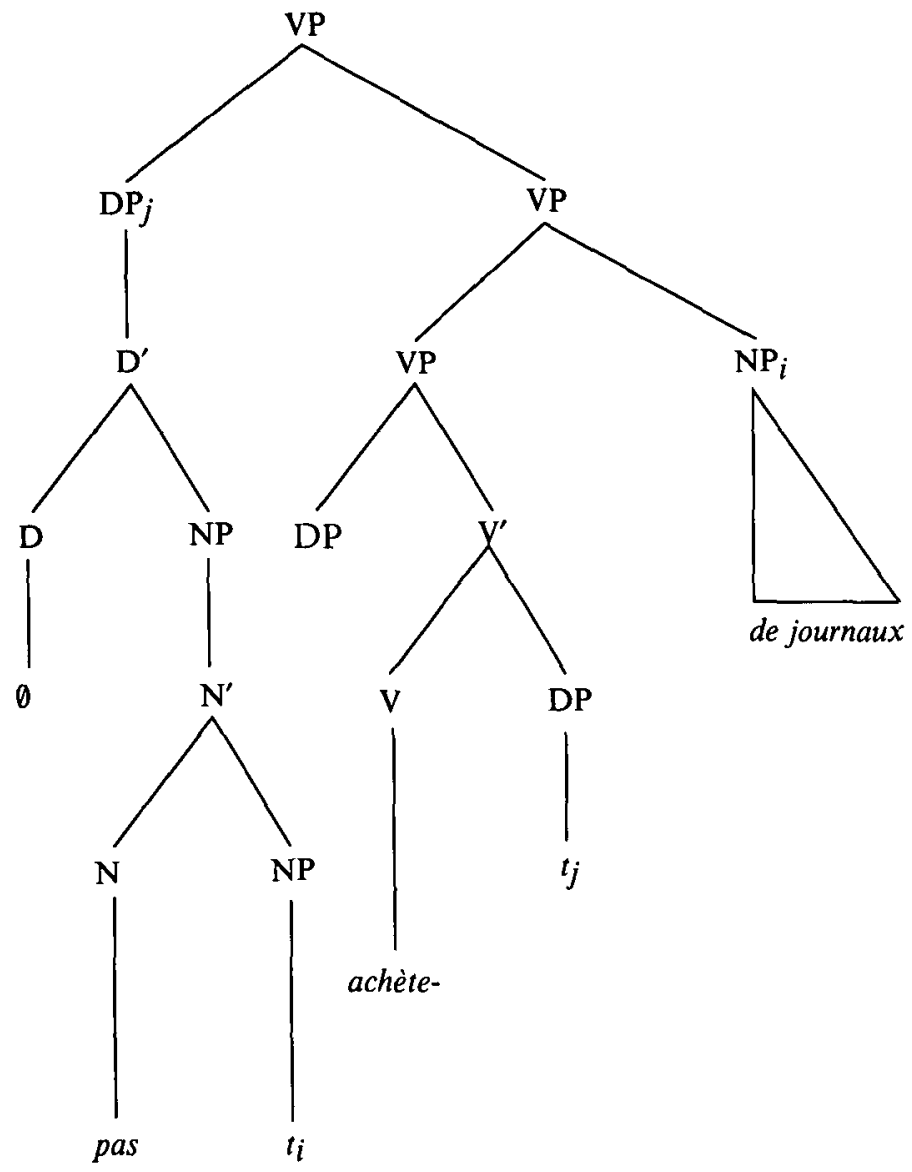

By adjoining the DP containing pas (or any other nominal quantifier) to VP, we can maintain our account of the strings in (27) and (28) above which Obenauer/our informants find unacceptable or somewhat bizarre respectively. We are also able to satisfy our intuition, discussed in subsection 2.3 above, that pas functions as an adverbial and that, as such, it should, at some level of representation, be adjoined to the constituent it modifies, here VP. We would like to suggest, however, that the DP does not appear in this VP-adjoined position with lexical content at S-structure; rather, we propose: (a) that a second application of Move- $\alpha$ adjoins this DP to TP; and then, (b) that a third application of Move- $\alpha$ moves it to SpecNeg, as shown in (33). (See Martineau (1992), who also proposes that, under certain circumstances, negative adverbs can climb up the tree structure by successive adjunction to functional maximal projections.) 
Paul Rowlett

(33)
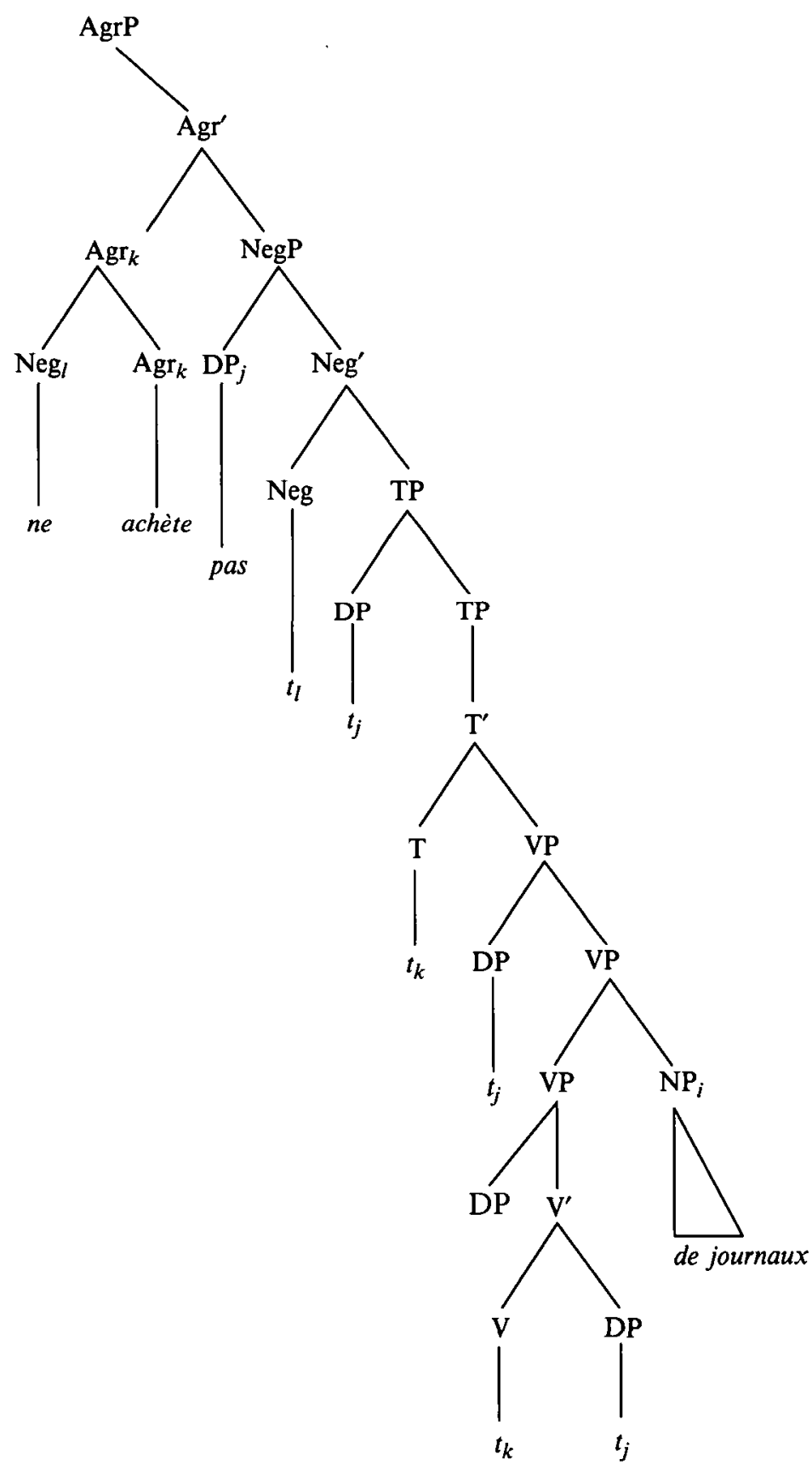
Once pas is in SpecNeg, the Neg Criterion is satisfied since pas can enter into a specifier-head agreement relation with $n e$, before ne cliticises onto the verb under the higher Agr node.

\subsection{Pas as a nominal quantifier with adverbial function (in other clauses)}

In this subsection, we shall turn our attention to clauses which do not contain a transitive verb and an idefinite direct object, i.e. clauses for which it would not be possible to posit that nominal quantifiers such as pas are basegenerated within the direct object. We shall therefore be considering: (a) clauses containing an intransitive verb, as in (18a) above; and (b) clauses containing transitive verbs and a definite direct object, as in ( $18 \mathrm{~b}$ ) above. In our analysis, we shall argue that, where pas is used to negate a proposition like (I8), pas is nevertheless not base-generated in SpecNeg. Quite apart from the reasons we detailed in subsections 2.I and 2.3 above, we shall, in addition, naturally wish to make our proposals here reflect as much as possible: (a) the proposals we made in the previous subsection; and (b) the syntax of other nominal quantifiers.

Thus, instead of thinking in terms of pas being base-generated in SpecNeg, we would like to argue that, in structures of type (18) above, the nominal quantifier pas is in fact being used adverbially (following the thrust of subsection 2.3) and that it is generated in a position in which adverbials are typically generated, i.e. in an adjoined position. In this respect, we are once again suggesting that the distribution of pas is essentially parallel to that of beaucoup and other nominal quantifiers used as VP adverbials. Consider again (22)-(25). What is of note with respect to the sentences illustrated in (22)-(25) above is the fact that each (b) and (c) sentence would be perfectly grammatical if beaucoup/ne . . pas were not present. This is clear from the acceptability of the four (a) sentences, which are indentical to their respective (b) and (c) counterparts, modulo beaucoup/ne . . pas. This state of affairs is in sharp contrast with what we encountered in the previous section where we considered the distribution of nominal quantifiers in clauses containing transitive verbs and indefinite direct objects. Consider again (17), repeated here for convenience as (35), along with (34):

(34) a. Je n'ai pas acheté $t$ de bouquins.

b. Il ne me donne pas $t$ d'argent.

(35) a. Le bouquiniste a vendu beaucoup de romans.

b. Le bouquiniste a vendu beaucoup des romans que tu lui as donnés.

c. Le bouquiniste a beaucoup vendu $t$ de romans.

d. Le bouquiniste a beaucoup vendu $t$ des romans que tu lui as donnés.

If we were to remove beaucoup or ne . . pas from these sentences, the remaining structures would no longer be grammatical, cf. (36) and (37) below. 
(36) a. *J'ai acheté de bouquins.

b. "Il me donne d'argent.

(37) a. *Le bouquiniste a vendu de romans.

b. *Le bouquiniste a vendu des romans que tu lui as donnés.

In an intuitive sense, we can attribute the ungrammaticality of the strings in (36)-(37) above by reasoning that, since pas (or beaucoup) is base-generated as the head $\mathrm{N}$ of an indefinite direct object, it forms an integral part of a vital A-position (even in QàD structures, whereby the association is maintained by an antecedent-trace binding relation). Thus, the absence of pas or beaucoup effectively means that part of the content of the vital A-position is missing, hence the ungrammaticality of (36) and (37) above.

Clearly, something different is going on in sentences (22)-(25) where the presence or absence of pas and beaucoup has no bearing whatsoever on the grammaticality of the sentence. Not surprisingly, the distribution of these elements resembles that of adverbials in this respect, whose presence is only rarely structurally compulsory. The explanation which is commonly proposed to account for the fact that the presence of adverbials is usually optional suggests that they typically occupy $A^{\prime}$ adjoined positions. What we would like to argue here is that, where pas and beaucoup, i.e. nominal quantifiers, appear in clauses where they are not associated with some indefinite direct object, they are generated in an adjoined position and assigned an adjunct $\theta$-role. The configuration is illustrated in (39) opposite which represents sentence $(38)$. 
Negative sentence adverbials

(38) Elise n'aime pas les monuments de Paris.

(39)

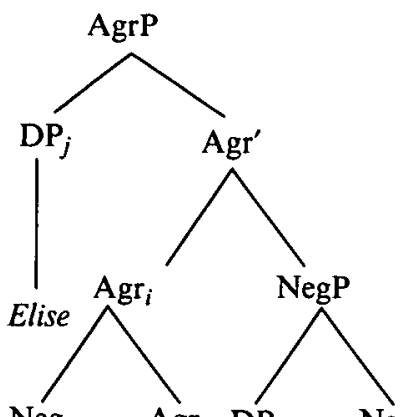

$\mathrm{Neg} / \quad \mathrm{Agr}_{i} \quad \mathrm{DP}_{k} \quad \mathrm{Neg}^{\prime}$
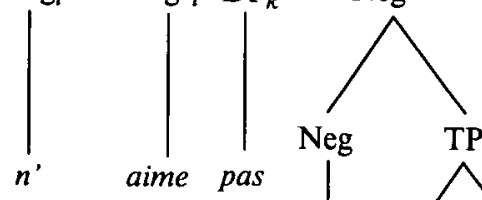

$n^{\prime}$

aime pas

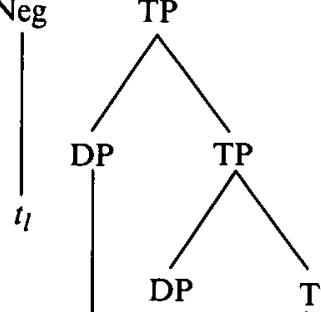

$t_{k}$
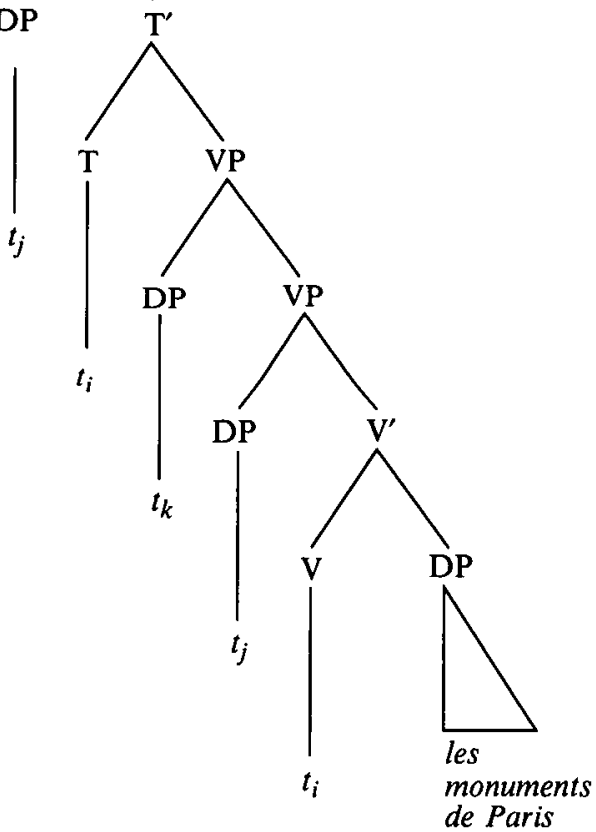
Given the account of pas which we proposed in the preceding subsection, i.e. along the lines of Obenauer's analysis of VP-quantification, it seems reasonable to believe that [DP pas] is VP-adjoined in the sentences under consideration here. In order to be associated with the negative clitic particle $n e$ to satisfy the Neg Criterion, we suggest that pas is subsequently adjoined to $\mathrm{TP}$, then moved to SpecNeg, exactly as in the previous section and as illustrated above in (39).

Having provided an analysis of the syntax of pas which, we feel, accounts for the data while avoiding some of the problems inherent in other current proposals, we now consider a number of issues which we are in a position to understand better.

\subsection{Further thoughts}

Attentive readers may have become somewhat sceptical in the light of our attempts to analyse pas in parallel fashion to beaucoup. They will perhaps have noted certain distributional asymmetries between indefinite DPs containing beaucoup, on the one hand, and those containing pas, on the other. In particular, although our analysis accounts for the fact that both types of indefinite DP appear in direct object position, we have made no mention of the fact: (a) that QàD is effectively compulsory in the case of pas, as illustrated in (40) and (4I) below; and (b) that indefinite DPs containing beaucoup can appear in subject position while those containing pas cannot, as shown in (42) and (43).

(40) a. J'ai vu [DP beaucoup de films]

b. Le professeur a corrigé [DP trop de papiers]

c. Monsieur le curé a bu [op assez de vin]

(4I) a. *Je n'ai vu [DP pas de films]

b. *Le professeur n'a corrigé [DP pas de papiers]

c. *Monsieur le curé n'a bu [DP pas de vin]

(42) a. Beaucoup de viande a été mangée chez Adrian ce soir-là.

b. Par la même occasion, trop de vin a été bu.

c Beaucoup de monde nous a vus dans un état pitoyable.

(43) a. *Pas de viande n'a été mangée chez Adrian ce soir-là.

b. *Pas de vin n'a été bu.

c. *Pas de monde ne nous a vus dans un état pitoyable.

We can account for the ungrammaticality of (4I) with reference to the Neg Criterion. If pas does not move out of VP to occupy SpecNeg, it will not be able to enter into a specifier-head agreement relation with ne, and the Neg Criterion will not be satisfied. In addition, there would arguably be two instances of negation in the same clause, each potentially voiding the other. 


\section{Negative sentence adverbials}

Similarly, the unacceptability of the strings in (43) can also be explained with reference to the Neg Criterion. Unlike objects, a clause subject is not assigned structural Case in its base position. Hence, it moves to SpecAgr at S-structure where it can be assigned nominative Case under specifier-head agreement with Agr. However, if the subject is an indefinite DP with pas as its ultimate head $N$, then pas will have moved higher than SpecNeg. This is because NegP is the complement of Agr and therefore below SpecAgr. Any movement of pas from SpecAgr to SpecNeg (to satisfy the Neg Criterion) would then be excluded in the way that all demotion movements are excluded, i.e. as an ECP violation.

\subsection{SUMMARY}

In this article we have attempted to apply the results of work by Obenauer and Battye, for example, to 'standard' implementations of the NegP hypothesis for sentential negation in French. Pollock's coverage of negation phenomena can, we think, be described not unfairly as sketchy. This is quite understandable given the import of the main aspect of the work, i.e. the presentation of a more articulated model of the syntactic representation of verbal inflection (the split-Infl hypothesis).

Nevertheless, we have had cause to doubt some of the claims Pollock makes in respect of sentential negation in French. In particular, we have found cause to argue against his claim that pas is generated in SpecNeg. Our argument was based on a consideration of three factors: (a) the incompatibility of Pollock's original account with the status of pas as a nominal; (b) an analysis of the relationship between pas and indefinite direct objects and of how this relationship cannot be adequately captured if pas is generated above VP; and, (c) a general concern for our theory of grammar to be as restrained as possible and a more specific desire to limit, subject to relevant empirical evidence, the number of types of position within the clause in which adverbials can be generated.

We went on to show that an alternative account of pas, based on work by Obenauer on 'quantification at a distance' and work by Battye on 'nominal quantifiers', not only achieves empirical adequacy but also avoids the problems we highlighted in Pollock's original account.

We demonstrated that pas is generated lower in clause structure than Pollock had envisaged. We showed that, as one of Battye's (1989) nominal quantifiers, pas is base-generated either: (a) as the ultimate head N of the NP complement of an empty D, i.e. in the case of an indefinite direct object; or, (b) as a DP in its own right (with adverbial function) adjoined to VP. In both cases, we have suggested that pas must move to SpecNeg at S-structure, where it can enter into a specifier-head agreement relation with the negative clitic ne under the Neg node.

We did not address the issues surrounding those other elements in French 
which are usually associated with the negative clitic particle ne, which we leave for the time being on the research agenda.

Author's address:

Department of Modern Languages,

University of Salford,

Salford M5 ${ }_{4} W T$,

England

\section{REFERENCES}

Abney, S. (1987). The English Noun Phrase in its Sentential Aspect. PhD dissertation, MIT.

Baker, M. C. (1985). The mirror principle and morphosyntactic explanation.

Linguistic Inquiry, 16:373-4I6.

Baker, M. C. (1988). Incorporation. A Theory of Grammatical Function Changing. Chicago: University of Chicago Press.

Battye, A. C. (1989). Aspects of Quantification in French in its Regional and Diachronic Varieties. Draft MS. University of York.

Battye, A. C. (I99I). Partitive and pseudo-partitive revisited: reflections on the status of 'de' in French. Journal of French Language Studies, I:2 I-43.

Belletti, A. (1990). Generalized Verb Movement. Turin: Rosenberg \& Sellier.

Belletti, A. (1992). Verb Positions; NP Positions. Evidence from Italian. MS. University of Geneva/Scuola Normale di Pisa.

Chomsky, N. (1974). The Amherst Lectures. Unpublished lecture notes distributed by Documents Linguistiques, University of Paris VII.

Chomsky, N. (198I). Lectures on Government and Binding. Dordrecht: Foris Publications.

Chomsky, N. (1986a). Knowledge of Language. New York: Praeger Press.

Chomsky, N. (1986b). Barriers. Cambridge, Mass.: MIT Press.

Emonds, J. E. (1976). A Transformational Approach to English Syntax. New York: Academic Press.

Gaatone, D. (1992). De négatif entre la syntaxe et la sémantique. Langue Française, 94: 93-102.

Haegeman, L. and Zanuttini, R. (I99I). Negative heads and the Neg Criterion. The Linguistic Review, 8:233-25I.

Kayne, R. S. (1975). French Syntax: The Transformational Cycle. Cambridge, Mass.: MIT Press.

Kayne, R. S. (I99I). Romance clitics, verb movement, and PRO. Linguistic Inquiry, 22:647-686.

Laka, I. (1990). Negation in Syntax: On the Nature of Functional Categories and Projections. PhD dissertation, MIT.

Martineau, F. (1992). Movement of Negative Adverbs in French. MS. University of Ottawa.

Milner, J.-Cl. (1978). Cyclicité successive, comparatives, et cross-over en français (première partie). Linguistic Inquiry, 9:673-693.

Obenauer, H.-G. (1983). Une quantification non-canonique: la quantification à distance. Langue Française, 58:66-88. 


\section{Negative sentence adverbials}

Obenauer, H.-G. (1984). On the identification of empty categories. The Linguistic Review, 4: I 53-202.

Ouhalla, J. (1990). Sentential negation, relativised minimality and the aspectual status of auxiliaries. The Linguistic Review, 7:183-231.

Pollock, J.-Y. (1989). Verb movement, universal grammar, and the structure of IP. Linguistic Inquiry, 20:365-424.

Rivero, M.-L. (I99I). Long head movement and negation: Serbo-Croatian vs. Slovak and Czech. The Linguistic Review, 8:3 I9-35I.

Roberts, I. G. (1991). Long Head Movement in Romance. Paper presented at the Workshop on Romance Syntax, Institute of Romance Studies, University of London, UK, I4. I2.9I.

Roberts, I. G. (I992). The Syntax of Inversion. Lecture course, GISSL, University of Girona, Spain.

Rowlett, P. (1992). On the D-structure position of negative sentence adverbials in French. University of Salford Department of Modern Languages Working Papers in Language and Linguistics, 12.

Rowlett, P. (forthcoming). Pas de deux. MS. University of Salford.

Selkirk, E. (1977). Some remarks on the noun phrase structure. In: Culicover et al. (eds.), Formal Syntax. New York: Academic Press, pp. 285-316.

Sportiche, D. (1988). A theory of floating quantifiers and its corollaries for constituent structure. Linguistic Inquiry, 19:425-449.

Williams, E. S. (1991). French pas and English not. Paper presented at the Workshop on Romance Syntax, Institute of Romance Studies, University of London, UK, I4. $12.9 \mathrm{I}$.

Zanuttini, R. (I99I). Syntactic Properties of Sentential Negation: A Comparative Study of Romance Languages. $\mathrm{PhD}$ dissertation, University of Pennsylvania. 